\title{
Contested Institutional Facts
}

\author{
Johan Brännmark ${ }^{1}$
}

Received: 29 June 2017/ Accepted: 12 March 2018/Published online: 2 April 2018

(C) The Author(s) 2018

\begin{abstract}
A significant part of contemporary social ontology has been focused on understanding forms of collective intentionality. It is suggested in this paper that the contested nature of some institutional matters makes this kind of approach problematic, and instead an alternative approach is developed, one that is oriented towards a micro-level analysis of the institutional constraints that we face in everyday life and which can make sense of how there can be institutional facts that are deeply contested and yet still real. The model is applied to two main examples, sexism and racism, and it is argued that on this approach it can make sense to understand both of them as institutions in our societies.
\end{abstract}

\section{Introduction}

Here are two broad, although hopefully not hopelessly unfair, generalizations about work done in social ontology over the last couple of decades. One is that it has often focused on collective intentionality. For instance, when Chant et al., in the introduction to a recent anthology (2014) discuss the state of the field, they note that out of what they call "the Big Five" theorists (Gilbert, Tuomela, Searle, Bratman, and Pettit), there is a "Big Four" whose accounts are all couched in terms of collective intentionality (Pettit being the exception). ${ }^{1}$ Similarly, Guala (2007) has suggested that there is a "Standard Model of

\footnotetext{
${ }^{1}$ Of these theorists, Searle $(1995,2010)$ and Tuomela $(2002,2013)$ are the ones most strongly focused on understanding institutions, while Pettit (1993, and together with List 2011) and Bratman (2014) are more focused on group thinking and agency. Gilbert (1989) also pulls in the latter direction, although her (2006) is oriented towards understanding society and politics in general.
}

Johan Brännmark

johan.brannmark@mau.se

1 Department of Global Political Studies, Malmö University, Nordenskiöldsgatan 1,

20506 Malmö, Sweden 
Social Ontology" in which collective intentionality is one key element. ${ }^{2}$ The second generalization is that if we look at, to use a Wittgensteinian phrase, the diet of examples nurturing much of the dominant theorizing in the area, it is relatively depoliticized, focusing on things like the value of money or taking walks or painting houses together, rather than more controversial political matters. Yet the idea that gender is a social construction is at the same time probably the paradigmatic example of something identified as such in contemporary social and political discourse, and claims that racism and sexism are structural or institutional features of our societies are commonplace. But social ontology often seems to take place at a distance from such discussions. ${ }^{3}$

One possible worry here is that the choice of examples is governed precisely by an interest in collective intentionality, and since it might seem prima facie more difficult to ascribe collective intentionality in cases characterized by contestation, such examples are set aside. Collective intentionality tends to involve some form of agreement on something, and while there is no reason to deny that collective intentionality is a real phenomenon, there is a risk that by taking it as paradigmatic of institutional reality, one will push other messier aspects to the side, perhaps even casting doubt on their existence. And yet social life, and presumably social or institutional reality as well, would partly seem to be characterized precisely by being simultaneously quite messy and quite ordered. There is accordingly reason to explore other kinds of accounts to a greater degree than what has tended to be the case. ${ }^{4}$ Using racism and sexism as primary examples of what could be institutional matters, but which are at the same time strongly contested, this paper will take some first steps in developing an understanding of institutional facts, and what grounds them, that will open up for contested matters still being matters of institutional fact.

\section{Institutions and the Possibility of Contestation}

Before saying anything about what it means for institutional facts to be contested a few words should be said about what institutions are taken to be. Although more will be said about how this idea should ultimately be understood, the basic approach taken here is in line with North's simple summary (1991, p. 97):

Institutions are the humanly devised constraints that structure political, economic and social interaction. They consist of both informal constraints (sanctions, taboos, customs, traditions, and codes of conduct), and formal rules (constitutions, laws, property rights).

What this means is that institutions define and govern our practices, where the latter can, in turn, be understood in Rawls' sense of "any form of activity specified by a

\footnotetext{
2 The other two elements being reflexivity (that social entities exist because we believe them to exist) and performativity (social entities are constantly re-created by members of the relevant community).

3 This is not to say that there is no such work in social ontology (more broadly understood). Haslanger (2012) is perhaps the leading theorist here, although more oriented towards social kinds than institutions; Jenkins (2017) is an example of someone starting in more traditional social ontology.

${ }^{4}$ In recent years, Elder-Vass (2012), Epstein (2015), and Guala (2016) are all examples of how social ontology is now developing into a richer field.
} 
system of rules which defines offices, roles, moves, penalties, defenses, and so on, and which gives the activity its structure" (1955, p. 3n1). There can be actions without institutions, there can possibly even be collective actions without them, but in human societies many of our actions take place within certain practices and are governed by institutions qua sets of constraints. The important thing about these constraints is that they are productive: as Rawls puts it, they define offices, roles, moves, penalties, defenses, and so on. Many actions would not even exist if the relevant institutions were not in place. However, in saying this it should also be recognized that what goes on here is not just that certain basic actions come to count as certain moves in a certain social context. The relevant institutions will usually add layers of social meaning to actions that already have social meaning, partly regulating actions that are already recognizable as socially meaningful actions, partly playing a constitutive role. ${ }^{5}$

From an ontological point of view, the main challenge set by starting from an account like North's is to provide an account of institutions that covers both the informal and implicit as well as the formal and explicit. North himself has suggested that "[i]nstitutions are the rules of the game in a society" (1990, p. 3) and that they "are perfectly analogous to the rules of the game in a competitive team sport" (1990, p. 4). Articulating constraints in terms of rules is perhaps a natural way to think, and there is probably some mileage to this kind of analogy, but one needs to be careful here since rules might mean at least two things, depending on whether we take an agent or an observer perspective ( $c f$. Guala 2016, pp. 54-55). On the one hand it might mean that there are rules in the sense that the relevant agents are governed in their actions by representations of these rules. Informal constraints will then more or less be unwritten rules: they are not formalized, but they are still something that people are aware of as rules. On the other hand, there might be rules in the sense that there are regularities in terms of the constraints that people recognize, even though this does not involve the application of rules. Rather than shared representations of rules, it could be a matter of sharing sets of similar-enough exemplars (representations of remembered instances) or prototypes (representations of clusters of properties which members of a category tend to share). ${ }^{6}$ While

\footnotetext{
${ }^{5}$ Is there a circularity problem here? This is often a worry for many approaches within social ontology, but while it is true that many institutions presuppose other institutions already being in place in order for them to come into existence, the present account does not presuppose that people who establish an institution have a concept of institutions or even constraints, nor does it presuppose that there are always already institutions in place for new institutions to come about (although complex institutions will probably require this). As will be explained below, for rudimentary institutions to come into being, all that is required is that people can engage in boundary-setting and boundary-upholding behavior in a way that establishes the relevant societal patterns of attitudes of actions, and this typically occurs through a gradual evolution, rather than some kind of joint quasi-decision to institute certain constraints.

6 While the so-called classical theory of categorization, according to which we categorize some $\mathrm{X}$ as a Y by using the individually necessary and jointly sufficient conditions for being a member of the category in question, is very much in line with how philosophers tend to analyze concepts, it has long been challenged in empirical studies of human categorization by adherents of prototype theory (e.g., Rosch 1978) and exemplar theory (e.g., Nosofsky 1988), who argue that we mainly categorize through similarity assessments instead. Note that the idea here is not that any one of these theories captures all forms of categorization - in fact, there is reason to doubt this ( $c f$. Machery 2009) - but simply that it should not be assumed that something like the classical theory captures everything.
} 
categorization by application of rules should typically be clear-cut (either something meets the relevant necessary and jointly sufficient conditions or not), categorization by exemplars and prototypes are always about making similarity assessments, a question of whether something is close enough to the relevant exemplars or prototype in order to count as that something, i.e., these are assessments that essentially involve gray areas. As regularities they might however still be rule-like enough for us, as observers, to make rule-like generalizations about them and to refer to them as rules. But even if this second sense of rule is perhaps even one that we realistically cannot do without in describing the workings of a society, we should be careful to not let this lead us into simply assuming that human agents are always governed by more or less exact correspondents to these rule-like generalizations. At any rate, on both senses of rules we can identify rules/regularities like these:

In a situation $S$, for an agent $\mathrm{A}$ to $\varphi$ counts as violating a constraint.

Violating a constraint can cover many different types of wrongs: breaking the law, not playing by the rules, violating a norm, committing a faux pas, being inappropriate, overstepping a boundary, and so on. Some of these might mean the same thing, some might differ in important respects. But they are all fundamentally about constraints. And at least from the outset, it does not seem obvious that they must all involve representations of rules among the relevant actors in order for these to identify certain actions as missteps.

Apart from an account of the nature of institutions, an ontological theory of institutions should also provide an account of how institutions or institutional facts are grounded, and here the present discussion follows Schaffer (2017, p. 2454) in assuming that " $[\mathrm{t}]$ he grounded is non-fundamental, and is generated by, dependent upon, and explicable on the basis of the grounds" and that "[t]o be socially constructed is to be grounded in distinctive social patterns." Although there is no room here to go into the variations on this particular theme that exist in the literature on social ontology, a standard idea is that the relevant social patterns are to be understood in terms of some interlocking complex of attitudes or actions that together amount to a state of collective acceptance. An institution accordingly exists because we collectively accept the set of constraints that together make up the institution. But exactly which kinds of patterns can be said to amount to there being collective acceptance?

One possible answer here might be called quasi-contractual: to understand collective acceptance as a form of agreement, which would involve an affirmative acceptance rather than a mere going-along-with. ${ }^{7}$ One advantage with this type of account is that it can help explain the normative character of institutions (by positively affirming the relevant set of constraints we bind ourselves to acting in

\footnotetext{
7 The clearest representative of this type of view is Gilbert, although her model is framed in terms of joint commitment rather than agreement (2006, pp. 215-217). Someone like Searle has a more voluntaristic approach, suggesting that the basic form of the operator that creates status functions is this: "We make it the case by Declaration that the Y status function exists in context C" (2010, p. 99). This should however presumably also be understood as some form of affirmative acceptance. Tuomela's model is more complex, but institutions are in general understood as based on we-mode thinking and collective commitments are an entailment of membership in a we-mode group (2013, p. 43).
} 
accordance with them), but also the conditional character of the relevant form of normativity (it is dependent not just on my acceptance, but on that of others as well). Of course, similar to what is the case with classic contract theory, the "deal" in question cannot be understood fully literally, at least not if we want a general theory of institutions, but rather in terms of individuals holding attitudes that functionally correspond to positively affirming, together, the relevant set of constraints. At the same time, even if we have to accept some degree of idealization in modelling if social ontology is to be able to get off the ground at all, this cannot make such models immune to counterexamples from actual social reality: we should at least be capable of pointing to rough actual correspondents to the features of social reality implied by the model. When it comes to the quasi-contractual model, whichever particular form it takes, there would seem to be at least two key implications: (1) that people must know what they are doing in some non-trivial sense, since without there being common knowledge in some interesting sense it is difficult to see how we can understand what is going in terms of some form of agreement ${ }^{8}$; and (2) that if people understand certain institutions as ones that are in place in their community or group, they should have a sense of being bound (quasi-contractually) by the relevant set of constraints, or as having reasons to act in accordance with them. With respect to certain oft-used examples, such as money, both of these characteristics would clearly seem to be in place. But what if we turn to more informal and implicit constraints?

If we look at racism and sexism as possible institutions both (1) and (2) appear more dubious. There is no room here to really make this case empirically, but if we look at contemporary Western societies, which are the ones where racism and sexism can perhaps be said to exist as informal and implicit institutions, rather than formal and explicit (as has been, and still often is, otherwise the case), there seems to be two types of contestation in play. To begin with, we have descriptive contestation, where many people simply disagree with the idea of racism and sexism being there as institutions in their societies. This is in sharp contrast with the assumption of common knowledge. But there is also normative contestation, where many people recognize racism and sexism as institutions in their societies, but reject the implication that this means that they have reasons to act in that way. And the rejection here is not just that there is an institution-provided reason that is then outweighed by some more important moral reason, but that they simply do not regard these as valid reasons. These two types of contestation, both descriptive and normative, seem to be perfectly able to coexist not just with each other but potentially also with sexism and racism as matters of institutional fact. Arguably, while there is perhaps a small minority who would both accept the existence of these institutions and the validity of the relevant reasons, the vast majority would actually seem to contest them in some way or other. With so much contestation, could there still be a way in which sexism and racism can exist, and even persist, as institutions? Although the quasi-contractual model can take many forms, we have arguably reached a point where it does not look like a promising approach.

\footnotetext{
${ }^{8}$ Assumptions of common knowledge have been standard fare in the relevant literature since introduced by Lewis (1969).
} 
A key to answering the question might instead lie in the fact that both of these forms of contestation are primarily about global or summative attitudes. And while we certainly hold such attitudes, most of everyday life takes place on a micro-level instead: millions and millions of small actions and reactions, many of which engender other small actions and reactions, and so on. It seems perfectly possible that we can contest certain institutions on a macro-level, both descriptively and normatively, while still performing actions on the micro-level that support the existence of these institutions. We have just not connected the dots. A possible way forward, then, is to focus on micro-level interactions and how these form patterns that can potentially exist and persist even in the face of widespread contestation on a summative level. But this requires an account of basic institutional facts that places them on the micro-level, rather than understanding them in terms of some kind of broader social agreement.

\section{Constraints as Hohfeldian Incidents}

Given the kind of approach to institutions adopted here, institutions are sets of constraints, i.e., they are fundamentally about sorting actions, or the moves that we and others can perform, into basic deontic categories: the permissible, the forbidden, and the obligatory. Constraints are, of course, essentially disabling: they prevent us from things. Yet they are also enabling: by systematically blocking certain moves they coordinate our behavior in ways that make possible other actions that would otherwise not have been possible. As social scientists we might, in trying to describe the workings of a specific society, try to articulate the sets of constraints that govern it, but as members of a community we often tend to be relatively inarticulate about these matters. We can, however, still have a quite robust intuitive sense of where the boundaries run and what counts as overstepping them.

If we are going to analyze what we owe to people on a micro-level, thus explicating the relevant constraints in more detail, the most classic approach is probably Hohfeld's influential schema for understanding rights and duties and the relations between them $(1913,1917)$. In its original form, the intent behind this schema was to explicate the legal relations in which we stand to each other, but as such, it is just a schema of deontic relations in an ordered system of such relations. It is a micro-level analysis in that it focuses on relations between specific individuals with respect to specific types of actions and there are four main building-blocks in the schema'

(1) A has a claim that B $\varphi$ if and only if B has a duty to A to $\varphi$.

(2) A has a liberty to $\varphi$ if and only if A has no duty not to $\varphi$.

(3) A has a power if and only if A has the ability to alter her own or another's Hohfeldian incidents.

(4) A has an immunity with respect to B if and only if B lacks the ability to alter A's Hohfeldian incidents.

\footnotetext{
9 The exact formulations here are not Hohfeld's, but based in the rearticulation by Leif Wenar (2005).
} 
What this means is that each incident always also has a direct correlate in the sense that whenever A holds an incident, some B holds a correlating incident:

$$
\begin{array}{ll}
\text { A has a claim } & \leftrightarrow \text { B has a duty } \\
\text { A has a liberty } & \leftrightarrow \text { B has a no-claim } \\
\text { A has a power } & \leftrightarrow \text { B has a liability } \\
\text { A has an immunity } & \leftrightarrow \text { B has a disability }
\end{array}
$$

Claims/duties and liberties/no-claims are the categories most directly structuring the moves that are open or closed to us. To the extent that I have liberties to act there are many different moves open to me, actions that are permissible. But with respect to certain other moves, people can have claims on me, either negative (which means that it is a forbidden or blocked move) or positive (which means that it is an obligatory move, i.e., no other move is permissible). The other two pairs of incidents are of the second order, being about the extent to which I can or cannot affect which moves that are open to me or others, i.e., they are ways in which I can or cannot change the deontic status of different actions. Although it is useful to separate these out as distinct incidents, because they identify important types of moves that can be made in an institutional context, it should be pointed out that ultimately they can also be understood in terms of duties, namely duties to accept certain changes in deontic status as valid changes and others as not.

Because it is a schema originally formulated to explicate legal relations in which we stand to each other, it should clearly be suitable for explicating the constraints that make up explicit and formal institutions, especially since an important feature of such institutions tends to be that persons possess powers to change the deontic status of persons: politicians who enact laws, judges who sentence criminals, administrators who grant applications, professors who pass students, and so on. All of these institutional roles are crucially centered on abilities to make changes in who owes whom what and how. The Hohfeldian schema also allows us to break down the complexes involved in what we colloquially refer to as rights into their component parts. A property right, for example, is at its core about having the liberty to use some thing as I see fit and having claims on others to keep their hands off it; but it also involves the power to transfer those liberties and claims to others (by giving them the thing in question) as well as immunities in relation to others (they cannot legitimately give away my things).

Now, the above examples involve explicit and highly formalized institutions, which also means that they can quite reasonably be understood as involving agents making their moves in the light of relatively clear representations of rules. But if we simply look at constraints as structuring interpersonal relations, the Hohfeldian schema could just as well be used to describe the relations between two persons. What is needed is a shared sense of boundaries structuring the social space that these two persons occupy, i.e., a shared sense of which moves that are open or not, and given that certain moves are made, which other moves that are then open or not. We have expectations about which actions that can be performed without receiving, or at least risking, pushback - as well as about which kinds of pushback that will count as overstepping and risk pushback in turn. There is a process of negotiation at work 
here, although not one that needs to be understood in terms of a deal having been made, that this is where we are to end up; instead, the process has simply come to settle in a particular place-in principle just provisionally, but quite possibly still relatively stable. The Hohfeldian schema is then a tool with which we can describe how that social space is deontically structured.

What this means is that already with respect to two persons it could (in principle at least) make sense to describe their relations in terms of certain social facts about the incidents structuring their relation, e.g., that person A possesses certain liberties in relation to person B. In the present context our interest is however in institutions and there are then two major differences to consider. One is simply about scale: institutions are societal distributions of constraints (or more specifically: Hohfeldian incidents). This means that even if, for many individuals, certain constraints are primarily structuring their relations with people in their immediate vicinity, what makes the fact that A possesses, say, a certain liberty in relation to B an institutional fact is that it is a token of a type of incident that persons occupying the relevant kind of social position tends to have. The other difference has to do with the policing of the relevant constraints: in the case of institutions, we are more or less all involved in policing them (and possibly policing the policing), which means that there are expectations in play about the kind of wider pushback, or at least disapproval, that we risk in making certain moves rather than others. Things accordingly become different in kind once we move beyond two-person cases. The important thing on a psychological level, however, is still simply that there is a shared sense of interpersonal boundaries, because this is what ultimately grounds the relevant constraints (which can be more precisely explicated in terms of sets of Hohfeldian incidents).

\section{Social Expectations and Opacity}

Boundary-setting and boundary-upholding exchanges between us can be understood as a way of coordinating and synchronizing our expectations about what will happen if one of us makes certain moves. We negotiate these boundaries and over time they can become settled without us having come to any actual agreement (in any nontrivial sense of the word), but simply in terms of people having developed an intuitive sense of in which ways it is safe to proceed in their daily lives. The social expectations that we form in relation to each other will be different from non-social expectations in that we are often, at least implicitly, aware of each other's expectations and aware of them being aware of our expectations. ${ }^{10}$ What this means is that if $\mathrm{A}$, as a matter of institutional fact, possesses a certain liberty in relation to $\mathrm{B}$, the typical expectation that people have with respect to persons like $\mathrm{A}$ and persons like $\mathrm{B}$ is that $\mathrm{B}$ will allow that behavior from $\mathrm{A}$ without pushing back. Although there might be individual differences in how aware people are of the social expectations that are in play with respect to specific actions, B will, in the case of it being an institutional fact that $\mathrm{A}$ has that liberty, typically have at least an

\footnotetext{
${ }^{10}$ For a seminal account of social norms in terms of social expectations, see Cristina Bicchieri (2006).
} 
implicit awareness of there being a sufficiently large subset of the relevant population that would expect B to allow A to act in that way, and which would disapprove of deviations from this script and would approve of A asserting his or her liberty in certain ways given any such deviations.

The details of how such social expectations can be coordinated and synchronized will have to be left for another occasion (and it should also be recognized that understanding the exact workings of such mechanisms will ultimately be a matter for sociologists and social psychologists rather than ontologists). The important thing here is simply to point to the type of distinctive patterns in attitudes and actions that can be understood as grounding institutional facts, and to see how this kind of grounding is compatible with the existence of both descriptive and normative contestation. While shared social expectations can be the product of a more or less conscious agreement on certain more or less explicit rules, they do not have to be. As already suggested, being synchronized in our responses to different moves that people might make could also largely be a matter of sharing sets of similar-enough exemplars or prototypes. This is a type of knowledge that can be fairly inarticulate and involve considerable opacity. ${ }^{11}$ We need to have a sense that enough of relevant others tend to treat two cases as similar enough to warrant a certain response, but we need not be able to fully understand why we do so.

For example, if I listen to a conversation between a man and a woman and they are taking up equal amounts of time in that conversation, I might see this woman as overstepping, as being too dominant in the conversation, and I might feel confident that others who listened to that same conversation would feel the same, perhaps even that if I did not make this assessment, those others would think that there was something amiss with my judgment. As already pointed out, the important thing here is that while the cue that actually triggers my judgment is that the woman takes up as much time as the man in talking, I need not recognize this as the relevant cue. I might think that the cue was simply that this person was too assertive or aggressive. Others might have similar responses to the situation as whole, but they too might be unclear about exactly what in the situation that triggers that response. We might not connect the dots. ${ }^{12}$ Hence the possibility of descriptive contestation: what we are then in disagreement about is precisely how to connect the dots.

With respect to normative contestation, again, the important thing is our actual patterns of responses in terms of seeing certain specific moves as appropriate or inappropriate. People can identify types of responses as sexist or racist in the abstract and think that being a woman or being a person of color does not really warrant having fewer moves open to one; but they can still, in a patterned way, regard specific actions by concrete persons occupying these social positions as overstepping boundaries-it is just that being a woman and being a person of color will not be consciously recognized as the cues to which they are responding. It is also perfectly possible that we systematically make these kinds of misidentifications

\footnotetext{
11 The notion of opacity is used by Thomasson (2003, p. 276), mainly with respect to macro-phenomena like recessions and inflation, but also in pointing to sexism and racism as potentially discoverable features of our societies.

12 A failure that could be innocent, but which might also be not entirely in good faith; certain forms of blindness can after all be clearly self-serving, e.g., see Mills (2007) for a discussion of white ignorance.
} 
with respect to the cues of our own responses, but still occasionally manage to see the responses of others more clearly and normatively contest their responses. Normative contestation could certainly go some way towards undermining an institution, but as long as a sufficient number of us still have synchronized responses where identifications of people as being a woman and being a person of color are important parts of what triggers seeing some concrete moves as inappropriate, then on an institutional level such concrete moves will, at the end of the day, count as inappropriate, as going beyond what one is at liberty to do. In terms of the attitudes and actions that ground institutional facts, e.g., that someone is under a duty to refrain from an action, to count as violating a constraint accordingly means that something tends to be seen, by people in the relevant peer group, as overstepping a boundary and that some kind of pushback that is perceived as warranted is likely. If this tendency is strong enough and wide-spread enough, one can say that there is an institutional fact in place about how the agent in question is constrained.

Instead of positing the existence of collective acceptance as a form quasiagreement that presupposes common knowledge about what has been agreed on and, hence, a certain level of transparency, the model developed here accordingly understands the Hohfeldian incidents that are in place simply in terms of our attitudes and responses to prototypical action-tokens being largely in synch, something which will gradually have evolved through repeated and gradually modified boundary-setting and boundary-upholding behavior in the relevant community. There can be regularities in terms of actions and responses without people having explicit ideas about what the rules are. We can choose to call this a form of collective acceptance, the words are not what matters here, but the important point is that it is compatible with both the presence of affirmative and transparent acceptance and the absence of it. Clearly, not all institutional facts are opaque, but some can be.

\section{Social Positions and the Distribution of Incidents}

If we take basic institutional facts to be about individuals possessing Hohfeldian incidents, institutions can be understood as stable and structured distributions of Hohfeldian incidents. ${ }^{13}$ A distribution being stable and structured can be the product of certain explicit rules being in place, but (as argued above) can also just be the product of an alignment in terms of boundary-setting and boundary-upholding micro-level behavior. Still, if we think that the relevant regularities typically make institutions rule-like in their structure, there is more that needs to be said here, because while the precise bundles of Hohfeldian incidents that we hold might actually be unique to each individual, there would still seem to be more structure to

\footnotetext{
13 It should be noted that it is possible for an action to count as wrong without it counting as having wronged someone. In terms of Hohfeldian incidents the status of such actions as wrong will be accounted for in terms of how, if I make a certain move, others will now be either permitted or perhaps even obliged to signal disapproval or sanction me in various ways. In fact, even with respect to those actions that do directly count as wronging someone, their being transgressions in an institutional sense essentially involves having implications for the moves that others can/should make in response to them.
} 
institutions than the bare fact that individuals have stable sets of such incidents. The incidents we have would often seem to involve different roles or offices, giving them a structured character.

In the general schema for rules or regularities adopted above (that in a situation $\mathrm{S}$, for an agent $\mathrm{A}$ to $\varphi$ counts as violating a constraint), there are three placeholders and the most important one in the present context is about how people are categorized as belonging to a certain class of agents or persons. In what follows here these categorizations will be referred to as social positions. Indeed what characterizes the Hohfeldian incidents that make up institutions is that they tend to be ones that we hold qua occupants of some social position-they come in typical bundles. Such social positions can be very varied in character. Many are relatively formalized: you can be a property owner, a marriage partner, a citizen, a university professor, a medical doctor, and so on. These are positions that are well-defined and where many of the Hohfeldian incidents involved in occupying such positions might even be legally regulated and enforced. But there are also social positions that are more informal: you can be a friend or a lover, parent or child, leader or advisor, and so on. These are roles that are not as well-defined, where there might be some, but not that many, written rules; and yet these are still social positions in the sense that there will be interlocking sets of expectations about the behavior of people occupying these roles and ideas about which actions that involve overstepping boundaries and which do not.

Whether formal or informal, what characterizes these social positions is that they involve certain typical bundles of Hohfeldian incidents. This does not mean that every person occupying a certain social position has exactly the same set of such incidents. When describing institutions we are generalizing, identifying patterns, but the exact constraints any given person actually faces will always be constantly negotiated and renegotiated in the more concrete relations that he or she has to other people. For instance, as a parent, there will be certain expectations on me that are quite generic and will typically be held by people I am not interacting with much. But layered on top of these there will be more specific expectations held by people with whom I interact more and who know me better. ${ }^{14}$ In describing institutions we are primarily describing the skeletal structure of constraints or Hohfeldian incidents, the typical starting bids (so to speak) in our interpersonal negotiations, not the exact character of the incidents held by each individual. These processes of negotiation and renegotiation will, of course, be much more pronounced when it comes to informal institutions, but even when it comes to legal rights and duties, these too also just provide us with a skeletal structure of typical incidents, where the exact character of how we really are constrained (or not) will depend on the more exact circumstances and relations characterizing our situation.

\footnotetext{
14 These descriptions are schematic and mainly intended as illustrative. It is also quite possible that there are several relevant sets of peoples that we have ideas about and whose behavior have varying effects on how we calibrate our expectations. For instance, in Dave Elder-Vass' account of norm circles he suggests that we need to distinguish between people's (1) proximal norm circles, those who have actually interacted with them in relevant ways, (2) imagined norm circles, those who they believe to endorse the norm in question, and (3) actual norm circles, the determinate set of people who actually would do so (2012, pp. 24-25). A similar division would probably be reasonable in the present context as well.
} 
Now, while the core of a social position, in the relevant institutional sense, is about nothing more than being a holder of a bundle of Hohfeldian incidents, there are at least three more elements at work here, one necessary and two auxiliaries. The necessary element is that there must be ideas in play about what qualifies someone as holding a certain social position. This can involve someone else having exercised Hohfeldian powers in a relevant way. For instance, if I want to become a legitimate medical doctor, I need to attend a school that has the power to confer on me the set of Hohfeldian incidents involved in being a doctor. But with many social positions there are instead informal rules of recognition in place which mean that if I fulfill certain criteria, anyone can (and is expected to) recognize me as occupying the relevant position and, hence, as holding the relevant set of Hohfeldian incidents. ${ }^{15}$ For instance, in order to be recognized by your peers as having parental duties you do not need an official ruling that you are a parent. Or if we look at gender as a social position, again, there will typically be informal rules of recognition in place, even apart from any official government assignment into gender categories. In fact, even in the cases where there are formal powers involved in granting us a certain bundle of Hohfeldian incidents, the social validity of these acts will ultimately rest on there being widespread recognition of the relevant holders of these powers as being holders of those powers, so even formal institutional facts ultimately rest on informal ones. For recognition to function systematically in actual practice there will typically be different tracking devices and recognition cues in play as well. Things like deeds of ownership and diploma allows us to keep track and things like uniforms and titles, or other more subtle but still relatively immediately recognizable cues, are used to signal how one has a certain social position. Unless the circumstances give people reason for doubt, such tracking devices and recognition cues will normally trigger the relevant responses more or less automatically. This is the first auxiliary.

The second auxiliary is more complicated, but arguably still often important. As such, a bundle of Hohfeldian incidents is simply about which moves that legitimately are open or not. It has no inherent rhyme or reason. It could in principle just be an unconnected heap of constraints. On an ontological level, as long as such bundles were reliably distributed, we would still have an institution in place. But in actual practice it seems quite unlikely that such distributions would be stable without there being some kind of motivating or organizing ideas backing up the composition of the bundles in question and making sense of why they take the shape that they do. These ideas would often seem to be functionalistic in some sense: medical doctors are supposed to treat our illnesses, and so it makes sense that they have the liberty (and the duty) to prescribe medicines, university professors are supposed to serve an educatory function, and so it makes sense that they have the power to pass students, and so on. Might this even be a necessary component? That would seem to be a step too far. Some distributions of incidents simply institutionalize hierarchies and differences in power-and while they certainly serve the function of doing just that, it need not be people's sincere belief in that function that supports the relevant distribution of duties, it could be fear of

15 The notion of rule of recognition comes from Hart (1961), but is used in a broader sense here. 
punishment or that they simply go along with what they are used to. While functionalistic ideas arguably play an important role in organizing and supporting many institutional facts, they accordingly seem best regarded as an auxiliary rather than an inherent part of institutions. ${ }^{16}$

Before proceeding to look specifically at sexism and racism and how they can function as institutions, there are two things that should be noted about this account of social positions. One is that it does not presuppose that people think of (what really are) contingent social positions as being contingent social positions. For example, a society might have an emperor that is widely believed to be a god. While people in that society might certainly recognize being emperor as a social role and recognize the bundle of Hohfeldian incidents held by the emperor as corresponding to incidents, primarily duties, that they themselves hold, they do not have to think of this as being a contingent social arrangement - they can understand it as part of the natural or divine order. The important thing for whether a certain social position exists is not that people have a correct understanding of it qua social position, it is simply that their actions and attitudes exhibit the patterns needed for grounding the stable existence of the relevant bundle of Hohfeldian incidents. And what goes for being emperor in this example might go for, say, being a man and being a woman as well. The other thing to note is that since Hohfeldian incidents are inherently relational and since social positions exist within larger institutional frameworks, one way of looking at and understanding specific social positions is through how they relate to other social positions. Indeed, already some the examples provided above point to how at least some social positions come in pairs, e.g., medical doctors and patients are one such pair, university professors and students another, and owner of a piece of property and non-owner of that piece of property yet another. This is not to say that all social positions need to be such that the Hohfeldian incidents that characterize them have a significant part of their corresponding incidents clustered in another corresponding social position, but that kind of arrangement does have a simplicity to it that perhaps makes it more reasonable to expect that such social positions endure over time- the respective positions help stabilize each other into a set structure.

\section{Sexism and Racism as Institutions}

For it to be possible to potentially understand phenomena like sexism and racism as institutions, it has been argued that institutions need to be understood in a way which means that they can exist even in the face of widespread descriptive and normative contestation. The preceding sections have been an attempt to show how this is possible. But this still leaves us with the task of explicating just how things like sexism and racism are supposed to function as institutions and when it can make sense to say that a society is institutionally sexist or racist in character. There will be

\footnotetext{
16 Of course, in Searlean social ontology, the imposition of status functions is at the core of establishing institutional facts, whereas on the present account such functionalistic ideas, when they are present, serve an auxiliary role instead. This auxiliary role might often be incredibly important, but functions are still not what institutional facts are essentially about.
} 
no room here for a detailed analysis of this, but it should be possible to at least provide an outline of what such an account would look like.

As already pointed out, many institutions involve social positions in the sense that there are classes of agents or persons that hold certain bundles of Hohfeldian incidents. Such social positions often also come in pairs, where many of the incidents characterizing them are such that the corresponding incidents are held by occupants of the other social position of that pair. While this implies a certain parity in terms of the number of incidents held, it clearly does not imply any equality in terms of how these incidents makes different moves available or unavailable to people. There can be significant deontic inequalities between people. Although there are contexts where possessing Hohfeldian liabilities will open us up for having beneficial incidents granted to us by others who have corresponding powers in relation to us, it is in general the case that while possessing left-side incidents (claims, liberties, powers, immunities) puts us in a position of freedom and control, possessing right-side incidents (duties, no-claims, liabilities, disabilities) puts us in a position of relative weakness in relation to those holding the correlating left-side incidents. Many social positions will involve both right-side and left-side incidents, but it is also clearly possible that there are social positions predominately characterized by one or the other. If this characterizes paired social positions, we can distinguish between (i) privileged social positions, which will be characterized by the relative extent to which their occupants have freedom from duty to as well as claims on people who have influence over their lives, most specifically on people who occupy the correlating social positions; and (ii) subordinated social positions, which will instead be characterized by the relative extent to which their occupants are bound by duties as well as having no-claims with respect to people who have influence over their lives, most specifically on people who occupy the correlating social positions.

A simple example of a privileged social position is that of being a propertyowner. It necessarily correlates with other people being non-owners (at least of that piece of property) and is a position characterized predominately by left-side incidents. Someone owning property is a standard-fare institutional fact, but the basic schema here can also be applied to social positions characterized by informal and implicit incidents. Social positions like being a man or being white would, if they are privileged positions, on this account then be characterized precisely by a predominance of left-side incidents, while the corresponding social positions, in this case being a woman or being a person of color, would be characterized by a predominance of right-side incidents. ${ }^{17}$ The most important incidents to look for here are probably claims and liberties, on the left side, and duties and no-claims, on the right side. These are the incidents that directly affect how, in everyday situations, different moves are available to us or not. Claims provide us with control over the actions of others and liberties provide us with freedom to act as we

\footnotetext{
17 Note that this kind of approach does not presuppose that social positions like being a woman and being a person of color are cleanly separable positions so that occupying the position of, say, being a woman of color, is simply a matter of occupying two distinct social positions that then add up to a more complex one. The deontic make-up of positions that we occupy can perfectly well be best analyzed in terms of more complex intersectional social positions; this is an empirical question.
} 
ourselves see fit, while duties mean that others have a say in what we do and noclaims mean that we do not have that kind of say ourselves. But powers/liabilities and immunities/disabilities are also important even in more informal contexts in the sense that persons who possess powers and immunities will get to exercise authority in determining what people's incidents are when this is unclear, while people possessing liabilities and disabilities are expected to acquiesce to such "authoritative" interpretations.

Note that the incidents that are of interest when making this kind of analysis are not just about how some people might be free to perform a variety of different moves in the conduct of their own lives, but also in which ways they are free to talk about and comment on members of other groups without this counting as disrespectful and, hence, as overstepping boundaries. To what extent is one free to talk about others in sweeping and generalizing terms? To what extent is one free to make fun of or even mock some people? To what extent is one obliged to listen to and take seriously what other people say? There is always an economy of attention and seriousness in the relations between people. We cannot completely attend to everything or take everything seriously and the distribution of the extents to which we are attended to and taken seriously will be governed by how we informally and implicitly understand our respective social positions in terms of our claims on each other-on what we owe to each other. The relevant constraints here will concern the behavior of listeners rather than speakers: to what extent can they neglect what certain people are saying without there being a sense that they have overstepped some boundary? If people's place in the economy of attention and seriousness is a subordinate one this will of course affect more than just bare amounts of attention, but also the extent to which we are understood to be owed trust in our credibility as witnesses and knowers. ${ }^{18}$

Since almost everything we do requires some form of cooperation from others, this kind of disadvantage will amount to something like an added tax that raises the cost in terms of effort required to achieve one's goals. If this kind of added tax systematically accompanies social positions like being a woman or being a person of color, that would seem to be a clear way in which a society can be said to be sexist or racist in an institutional sense-not because certain moves are strictly blocked but because many sustained courses of action will over time be more costly in terms of effort. Occupying a subordinated position in this sense will also typically involve being less protected against microaggressions in everyday interactions (Sue et al. 2007). ${ }^{19}$ Other people will be at liberty to act aggressively or at least assertively with respect to one, a liberty which they do not have with respect to

\footnotetext{
18 Cf. Fricker (2007, Chapter 1) on what she calls testimonial injustice.

19 An example provided by Sue is when he and another person of color were taking a flight and were picked out and asked by a flight attendant to move to the back of the plane in order to get a better distribution of weight on the plane. Assuming that there was a real need to improve the weight distribution, Sue and his co-passenger still felt that they had been treated as second-class citizens, while the flight attendant, when they protested, strongly rejected the idea that she had any racist motives. On the account provided here, this type of situation can be analyzed in terms of how Sue and his co-passenger were, compared to the white passengers, less protected in terms of informal and implicit Hohfeldian incidents against moves that potentially affect them negatively.
} 
others. These kinds of mechanisms can be subtle in their workings, but they are nevertheless ultimately about how the distribution of constraints will affect the possibilities for people to exercise control over their lives.

This kind of analysis does not presuppose, for sexism and racism to be institutions, that people hold explicitly sexist or racist attitudes. It is enough that we systematically respond to certain cues in certain patterned ways. Many things can serve as the relevant cues, but skin color and different gender markers seem to be obvious examples. ${ }^{20}$ Of course, since this is an account of how societies can be sexist or racist in an institutional sense, not what it means for individual persons to be so, it certainly does not rule out that people have explicitly sexist or racist attitudes or beliefs. It might even be (highly) unlikely that societies will have such characteristics without there being any explicitly sexist or racist attitudes in play; but with respect to persons who occupy privileged positions like being a man and being white, this is at its core an account of what is involved in being a beneficiary of a sexist or racist distribution of informal and implicit incidents. ${ }^{21}$

As already pointed out, different kinds of organizing or motivating ideas often tend to accompany and support social positions and make sense of them in the eyes of people in that society. It is accordingly difficult to see how a society can be institutionally sexist or racist without there being widespread illusory beliefs about "how men and women are" and "how people of color are" ( $c f$. Shelby 2002), i.e., more or less functionalistic ideas about groups of people. But such beliefs need not be understood as sexist or racist by people themselves. They themselves might just see these beliefs as describing reality and, in fact, to some extent such beliefs can even capture aspects of actual behavior-it is just that the behavior in question is actually then the product of an institutional arrangement partly held up by those very beliefs, not anything that provides a genuine rationale for those institutions being in place.

This type of analysis is ultimately descriptive; it does not locate blame anywhere, it is simply about identifying possible inequalities in terms of how incidents that govern how much freedom and control we have in social life are distributed. One consequence of this descriptive character is that, even to the extent that we do identify significant inequalities, this approach does not say anything about exactly how bad these are-or even whether they are bad at all. Sexism and racism serve as analytical terms here. Of course, given that we also happen to hold egalitarian moral and political views, an unequal distribution of informal and implicit incidents should certainly bother us, but this is still a distinct moral and political stance that we take with respect to the analysis we have made. It is certainly possible to

\footnotetext{
${ }^{20}$ Arguably, there is especially in the case of gender, a very pronounced performative component, where many people quite strongly signal gender belonging, thereby providing recognition cues, in ways that facilitate an easy categorization of them. But racial categorizations are hardly about skin color alone, since a variety of factors might, for example, determine whether certain persons of color can pass for white or not.

21 The question of what it means for a person to be sexist or racist will accordingly be left aside here; for a good overview and discussion of this issue, see Glasgow (2009).
} 
formulate normative accounts of privilege instead, ${ }^{22}$ but at least given our startingpoint here-that we want an account that covers and makes sense of both contested institutional facts of the kind considered above and all other institutional facts as well-a descriptive theory is what we should want. We should want a social ontology that is relevant to political theory, not one that has been turned into political theory.

Finally, it should be pointed out that with respect to the core features of the general approach to institutions presented here, racism and sexism only serve as examples. The approach itself, if accepted, does not commit us to any specific answer to the question of whether racism and sexism are institutional or not in our societies. It only provides an account of how they can be matters of institutional fact even in societies where that matter is heavily contested, both normatively and descriptively. In providing a set of conceptual tools, the present approach tells us what to look for, not what is actually there to be seen.

Acknowledgements This paper was originally presented at the workshop Non-Ideal Social Ontology II at Stockholm University, and I am very grateful to all the participants, and especially the organizers, Åsa Burman and Katharine Jenkins, for the fruitful discussions there. I also wish to thank Anna-Sofia Maurin for detailed comments on an earlier draft, as well as two anonymous referees, who really helped improve the paper. My work on it has been enabled by a position as Research Fellow granted by the Royal Swedish Academy of Letters, History and Antiquities.

Open Access This article is distributed under the terms of the Creative Commons Attribution 4.0 International License (http://creativecommons.org/licenses/by/4.0/), which permits unrestricted use, distribution, and reproduction in any medium, provided you give appropriate credit to the original author(s) and the source, provide a link to the Creative Commons license, and indicate if changes were made.

\section{References}

Bailey, A. (1998). Privilege: Expanding on Marilyn Frye's 'oppression'. Journal of Social Philosophy, 29, 104-119.

Bicchieri, C. (2006). The grammar of society. Cambridge: Cambridge University Press.

Bratman, M. (2014). Shared agency: A planning theory of acting together. New York: Oxford University Press.

Chant, S., Hindriks, F. R., \& Preyer, G. (2014). Beyond the big four and the big five. In S. R. Chant, F. Hindriks, \& G. Preyer (Eds.), From individual to collective intentionality. New York: Oxford University Press.

Elder-Vass, D. (2012). The reality of social construction. Cambridge: Cambridge University Press.

Epstein, B. (2015). The ant trap. New York: Oxford University Press.

Fricker, M. (2007). Epistemic injustice. Oxford: Oxford University Press.

Gilbert, M. (1989). On social facts. Princeton: Princeton University Press.

Gilbert, M. (2006). A theory of political obligation: Membership, commitment, and the bonds of society. New York: Oxford University Press.

Glasgow, J. (2009). Racism as disrespect. Ethics, 120, 64-93.

\footnotetext{
22 One example being the account proposed by Alison Bailey (1998) of privilege as unearned assets conferred systematically. Given that we are interested in the social reality of privilege it does however seem best to not build matters of desert into the account, but to stick with a naturalistic account.
} 
Guala, F. (2007). The philosophy of social science: Metaphysical and empirical. The Philosophy Compass, 2, 954-980.

Guala, F. (2016). Understanding institutions. Princeton: Princeton University Press.

Hart, H. L. A. (1961). The concept of law. Oxford: Clarendon Press.

Haslanger, S. (2012). Resisting reality: Social construction and social critique. New York: Oxford University Press.

Hohfeld, W. N. (1913). Some fundamental legal conceptions as applied in judicial reasoning. The Yale Law Journal, 23, 16-59.

Hohfeld, W. N. (1917). Fundamental legal conceptions as applied in judicial reasoning. The Yale Law Journal, 26, 710-770.

Jenkins, K. (2017). What women are for: Pornography and social ontology. In M. Mikkola (Ed.), Beyond speech: Pornography and analytic feminist philosophy. New York: Oxford University Press.

Lewis, D. (1969). Convention. Cambridge: Harvard University Press.

List, C., \& Pettit, P. (2011). Group agency: The possibility, design, and status of corporate agents. New York: Oxford University Press.

Machery, E. (2009). Doing without concepts. New York: Oxford University Press.

Mills, C. W. (2007). White ignorance. In S. Sullivan \& N. Tuana (Eds.), Race and epistemologies of ignorance. New York: SUNY Press.

North, D. C. (1990). Institutions, institutional change and economic performance. Cambridge: Cambridge University Press.

North, D. C. (1991). Institutions. The Journal of Economic Perspectives, 5, 97-112.

Nosofsky, R. (1988). Exemplar-based accounts of relations between classification, recognition, and typicality. Journal of Experimental Psychology, 14, 700-708.

Pettit, P. (1993). The common mind. New York: Oxford University Press.

Rawls, J. (1955). Two concepts of rules. Philosophical Review, 64, 3-32.

Rosch, E. (1978). Principles of categorization. In E. Rosch \& B. Lloyd (Eds.), Cognition and categorization. NJ: Lawrence Erlbaum Associates, Hillsdale.

Schaffer, J. (2017). Social construction as grounding; or: Fundamentality for feminists, a reply to Barnes and Mikkola. Philosophical Studies, 174, 2449-2465.

Searle, J. (1995). The construction of social reality. New York: Free Press.

Searle, J. (2010). Making the social world. New York: Oxford University Press.

Shelby, T. (2002). Is racism in the 'heart'? Journal of Social Philosophy, 33, 411-420.

Sue, D. W., et al. (2007). Racial microaggressions in everyday life: Implications for clinical practice. American Psychologist, 62, 271-286.

Thomasson, A. (2003). Foundations for a social ontology. ProtoSociology, 18, 269-290.

Tuomela, R. (2002). The philosophy of social practices: A collective acceptance view. Cambridge: Cambridge University Press.

Tuomela, R. (2013). Social ontology. New York: Oxford University Press.

Wenar, L. (2005). The nature of rights. Philosophy \& Public Affairs, 33, 223-252. 